\title{
THE AETIOLOGY OF TRACHOMA*
}

A critical review of present knowledge

\author{
BY \\ J. O. W. BLand \\ FROM THE MEMORIAL OPHTHALMIC LABORATORY, \\ GIZA, EGYPT
}

Ar the present time, only two theories of the aetiology of trachoma are generally accepted, the virus theory and the rickettsial theory. I believe that these two theories are not mutually incompatible but can be reconciled. The conflict is indeed one of nomenclature rather than bf fact and largely depends on what we choose to call a rickettsia and what we choose to call a virus. The evidence so far accumulated leads to the conclusion that trachoma is a specific infectious disease, not caused by any cultivable bacterium, but due to a filter passing agent which is almost certainly-identical with the elementary and initial bodies found in the inclusion bodies (Prowazek-Halberstaedter inclusions). Further, I shall attempt to show that the evidence that any rickettsial body other than these elementary and initial bodies is the cause of trachoma is inacceptable and shall discuss the relationship of these bodies to the viruses and the rickettsiae. Since much of the evidence to be presented is dependent upon experiments in animals and since there is some reason for doubting the validity of such experiments, it will be necessary to discuss this question first.

\section{1.-The validity of animal experiments in trachoma research}

It is now generally accepted that trachoma can be conveyed only to apes and monkeys and that other animal species are insusceptible. The disease produced by inoculation in apes and monkeys is not identical with that in man. The usual criterion adopted in these animals has been the production of a crop of follicles on the conjunctiva. Wilson ${ }^{1}$ has drawn attention to the following characteristics of this reaction.

1. Inclusion bodies, are very rarely found in conjunctival scrapings.-There is only one report ${ }^{2}$ of their being found in any species of monkey. In apes they have been reported more often but still only rarely.

2. No follicles are ever formed on the tarsus, they oecur only in the fornices.

* Received for'publication, October 26, 1944. 
3. There is no vascularization of the cornea.

4. There is no subsequent scarring of the conjunctiva.

Now in man, the presence of inclusion bodies, the formation of follicles on the tarsus, vascularization of the cornea and scarring of the conjunctiva are the four cardinal diagnostic signs of trachoma. Their absence in monkeys therefore casts doubt on the claim that trachoma can be conveyed to these animals. In the case of the Macacus rhesus, Julianelle ${ }^{3}$ has made a careful examination of the follicular reaction and has shown that it is specific for trachoma and tannot be produced by inoculation of material from other types of folliculosis, nor by viruses, bacteria or chemical agents, but until recently no one had attempted the critical test of inoculating material from experimental trachoma in monkeys into human volunteers. This has now been done using the grivet monkey (Lasiopyga griseoviridis) ${ }^{56}$, and it has been established that the grivet monkey is susceptible to trachoma, in spite of the fact that it does not show the four cardinal signs. Further, it is established that the virus multiplies in the grivet up to at least four passages and that material from the fourth passage in the grivet is infective for man.

If this were the whole story the position would now be most satisfactory, but unfortunately a further complicating factor enters into the situation: the occurrence in monkeys of a spontaneous folliculosis. A spontaneous non-trachomatous follicular disease of the conjunctiva is not uncommon in man and many other animals. Nicolle and Lombroso ${ }^{4}$ have reported it in rabbits, chimpanzees and lower monkeys. Wilson ${ }^{1}$ describes it in grivet and rhesus monkeys and a chimpanzee. Julianelle ${ }^{3}$ also mentions it (presumably in the rhesus) in describing his experiments on the specificity of the trachomatous reaction. Recent observations have shown ${ }^{56}$ (1) that wild grivet and vervet (Lasiopyga griseoviridis and pygerythra) and other monkeys, freshly arriving in Cairo from the Sudan and Central Africa, may already have the disease, (2) that it may develop spontaneously, within six weeks of their arriwal, in every one of a batch of grivets and young baboons (Papio hamadryas) kept in captivity 57 , (3) that while the number of follicles is usually less and their situation not the same as in a typical trachomatous reaction, nevertheless in approximately one-third of the cases the disease is indistinguishable from a reaction to inoculated trachoma. I, therefore, consider that we should not accept a reaction in any species as trachomatous unless it passes examination by at least one of the following tests :-

1. It reproduces the four cardinal sigms of trachoma described above. 
2. It is shown by the methods used by Julianelle ${ }^{3}$ in the case of $M$. rhesus that the reaction is specific for trachoma.

3. It is proved to be trachoma by inoculation into human beings with the production in them of typical trachoma.

Should only condition 1 or 2 be fulfilled it must also be known that the reaction does not occur, or only very rarely occurs as a spontaneous disease in the species under examination. Further, it seems that the grivet (Lasiopyga griseoviridis) in spite of its proved susceptibility to trachoma, the vervet (L. pygerythra)' and the baboon (Papio hamadryas) are unsuitable for trachoma experiments because they too frequently suffer from spontaneous folliculosis. Experiments in which they have been used must be disregarded. The M. rhesus I have not myself had an opportunity of studying. Dr. R. P. Wilson, in a personal communication, tells me that he found spontaneous folliculosis less frequently in the rhesus than in other species. Julianelle ${ }^{3}$ in his careful studies of trachoma does not mention it as a serious complication of his experiments. Therefore, it appears that we may tentatively accept positive results in the rhesus but I would urge great caution in accepting conclusions based on negative results. Julianelle ${ }^{3}$ has shown that only about 50 per cent. of these monkeys are susceptible to trachoma. In such a case,' if we use four animals for a test, there is only a 21 to 1 chance against all four animals failing to react even when a fully virulent inoculum is used. With six animals, the odds rise to 80 to 1 , with nine to 369 to 1 . Therefore, negative results in rhesus monkeys should not be accepted unless at least six or more animals have been used.

These facts must be kept in mind when assessing the value of any report of experimental work on trachoma.

\section{II.-Trachoma is a specific infectious disease}

This is now undoubted. Wernicke first proved it in 1823 by inoculating men with excised follicles from a patient of $2 \frac{1}{2}$ years standing. Since that time, similar experiments have repeatedly. been performed and it is now certain that inoculation of trachomatous material in healthy human beings will produce trachoma. Julianelle ${ }^{3}$, reviewing the literature, records that 108 volunteers have been inoculated of whom 73 became infected-a 63 per cent. 'positive result. He considers the failures due (1) to material for inoculation having been taken in a late; non-infectious stage of trachoma, (2) to resistance of the individual, for in some cases a person has succumbed to infection only after repeated attempts. Such transference of disease from one person to another is only explicable on the basis that the material inoculated contains an infectious agent. 


\section{III.-The infectious agent is not a cultivable bacterium}

In the past, a very large number of different species of bacteria have been described as the cause of trachoma (vide Julianelle ${ }^{3}$ ). Their very variety casts doubt on their claims. Furthermore, no cultivable bacterium has yet been shown to produce trachoma when experimentally inoculated into man. Bact. granulosis described by Noguchi ${ }^{5}$ as the cause of trachoma is no exception to this rule. Seventy-four attempts to infect man with cultures of. this organism have now been reported. All but two have failed. In these two, the volunteers had both previously suffered from trachoma. Since healed trachoma is capable of acute recurrence, these two positive results are inacceptable. Comparing this with the comparative ease with which tissues from trachoma will reproduce the disease, it is obvious that the agent of trachoma has not been cultivated.

\section{IV. - The infectious agent is filterable}

It must be admitted that, in the majority of experiments made to demonstrate the filterability of the virus of trachoma, filtrates have been non-infective even when the original material before filtration has been proved infective. The number of successful filtrations reported is very small indeed. This, however, is one of those cases where one well controlled positive result may legitimately be held to outweigh a large number of negatives for the following reasons : (1) In all filtration work on viruses it is well known that adsorption by the filter plays an important part. Filtrates always show a lower potency than the original material filtered. Where this material is rich in virus, it is able to satisfy the adsorptive capacity of the filter and yet allow some virus to pass. When, however, the material has a low virus content, the filter may remove the whole of it and allow none to pass. In the case of trachoma we are dealing with tissues which do not have a high content of virus and moreover we cannot obtain material in large quantities. The richest suspensions we can prepare contain much less virus than the average suspension prepared from tissues infected with such a virus as vaccinia; (2) Reasons will be given in the next section for believing that the virus of trachoma consists of the initial and elementary bodies which form the inclusions. These initial and elementary bodies are found much more rarely outside the cells than is the case with the similar bodies found in inclusion blennorrhoea and psittacosis in both of which diseases filtration is more easily accomplished than in trachoma. The epithelial cells, which.contain the trachoma inclusions, are themselves too large to traverse filters and unless in preparing 
our suspension for filtration a large number of the inclusion bearing cells are ruptured, the amount of virus present in the form of free elementary bodies, that is in a form in which it is capable of being filtered, will be considerably less than would be thought from a titration of the infectivity of the suspension. It is probable that the ordinary method of preparing suspensions by grinding the tissues in a mortar does in fact leave many of the cells unruptured.

Bearing in mind then these two facts, the adsorptive capacity of filters, and suspensions with a low content of trachoma virus in a filterable form, we should expect most attempts at filtration to fail. The positive experiments must therefore be accepted as proof of the filterability of the virus if they pass scrutiny from other points of view. Let us examine them :

(a) Filtration through filter candles.-Bertarelli and Cechetto ${ }^{2-6}$ infected one Macacus cynomolgus with a filtrate from a Berkefeld candle. Nicolle, Cuénod and Blaizot ${ }^{7-8}$ infected one $M$. inuus and one chimpanzee with a filtrate from a modified Berkefeld candle: Since the trachomatous reaction in these three species has not been proved to pass any of the three tests demapded in Section 1 of the article, these experiments must be discarded as inconclusive. This leaves three reports of successful infection of $M$. rhesus. Julianelle and Harrison ${ }^{9}$ report a single positive experiment where three out of six $M$. rhesus were infected with filtrate through a Berkefeld $\mathrm{V}$ candle. The original material was infective, the filtrate was bacteriologically sterile. The experiment was, therefore, well controlled and must be accepted.

Julianelle ${ }^{3}$ further reports two experiments in which filtrátes ' from Berkefeld $\mathrm{V}$ candles infected two out of four and one out of four M. rhesus. The original material was infective, the filters 'were tested with cultures of B. prodigibsus.- These experiments must also be accepted.

Olitsky, Knutti and Tyler ${ }^{10}$ report one experiment in which one M. rhesus out of three was infected with filtrate from a Berkefeld V. filter. The original material was doubtfully positive. The filters were-controlled by filtration of $\mathrm{B}$. prodigiosus both before and after filtration of trachoma. This experiment is also trustworthy.

(b) Filtration through collodion membranes.-Collodion membranes are considerably thinner than filter candles, and in the hope of reducing the factor of adsorption some workers have used them. Some experiments of Stewart ${ }^{11}$ show, however, that a collodion membrane may have a considerable adsorptive power, and in point of fact attempts to filter trachoma through such membranes have been less successful than those with filter candles. Let us examine the positive claims. 
Stewart ${ }^{11,12}$ reports three well controlled experiments where filtrates from filters impervious to B. prodigiosus were infective for animals. The animals used were grivets and baboons. Since we now know that these animals are very prone to spontaneous folliculosis we cannot accept Stewart's findings which may posssibly have been falsifled by the occurrence of this disease.

Thygeson and Proctor ${ }^{13}$ report three successful filtrations. The filters were controlled against passage of bacteria by cultures of the filtrates, which were negative. The animals used were African Sphinx baboons which the authors had found uniformly susceptible to trachoma. As Stewart ${ }^{58}$ has said, there are no records of the frequency of spontaneous folliculosis in these animals and the reaction in them has not been shown to pass the tests here demanded. Until it has, these experiments must also be discarded on strict critical analysis.'

There remains a single, but admirable, experiment by Thygeson, Rroctor and Richards ${ }^{14}$ in which a filtrate from a collodion membrane of A.P.D. $0 \cdot 6 \mu$, inoculated into the eye of a human volunteer, produced typical trachoma with inclusion bodies and free elementary bodies in large númbers. The original material was not tested for infectivity but contained inclusion bodies. The filtrate was bacteriologically sterile and contained elementary bodies. Discs cut from the same collodion sheet as the membrane were impermeable to Bacterium granulosis and $H$. influenzae but passed elementary bodies of molluscum contagiosum. This well controlled, experiment is eminently acceptable.

To sum up then we are left with four trustworthy experiments in the M. rhesus and one in man. If we accept the results in $M$. rhesus, as I think we may, this series of successful filtrations should be considered to prove the filterability of trachoma. If, however, we reject results in the rhesus we are left with the single experiment of Thygeson, Proctor and Richards which, excellent as it is, requires repetition in order to put the matter beyond doubt.

\section{V.-The relationship of the inclusion bodies to the infective agent}

In the case of most other viruses which form elementary bodies (E.B.s) these have now been -accepted as being the virus itself. Furthermore, in the case of some viruses, e.g., fowl-pox, psittacosis, vaccinia, ectromelia of mice, the inclusion bodies are composed of masses of these elementary bodies. The occurrence in trachoma of both free E.B.s and inclusion bodies composed of them, taken with the evidence that the agent of trachoma is 
filterable, is itself strong prima-facie evidence that the E.B.s of trachoma are the infective agents. We shall find that the evidence for this hypothesis consists of two parts: (1) Direct evidence; (2) Evidence from analogy with other viruses.

(1) Direct evidence that the E.B.s and Inclusions of Trachoma are the causal agents.-(a) It is well known that inclusion bodies are found more frequently in the early acute stages of trachoma than in the later more chronic stages. The most conclusive single demonstration of this is that of Julianelle ${ }^{15}$ but in his review of the literature ${ }^{3}$ he shows that it has repeatedly been observed by others. In studying inoculated trachoma in two human volunteers, Bland ${ }^{56}$ also found inclusions most numerous at the very onset of the acute infection, thereafter their numbers decreased as the disease passed into its chronic stage. This is precisely what we should expect if the inclusions contained the infective agent.

(b). Inclusions are constantly present in the acute phase of trachoma if sufficient care and trouble is taken in searching for them. ${ }^{16}{ }^{17}$.

(c) Inclusions similar to those of trachoma are never found in normal human eyes or in any human ocular disease except inclusion conjunctivitis (inclusion blennorrhoea and swimming bath conjunctivitis) and in ocular lymphogranuloma inguinale both of which conditions have been proved to be due to viruses related to, but distinct from, trachoma.

(d) Juliánelle ${ }^{15}$ has shown that trachomatous tissues containing inclusions possess approximately twice the infectivity for $M$. rhesus of tissues in which inclusions cannot be demonstrated. Mixtures containing approximately equal amounts of tissues with and without inclusions have an infectivity approximately half way between. The infectivity of tissues is thus closely related to the presence of inclusions.

(e) The inclusion body is almost certainly not an artefact. The idea that virus inclusions in general are non-specific formations produced by nuclear extrusion, nuclear or cytoplasmic degeneration, phagocytosis of cell débris or bacteria, has been repeatedly put forward but is not now accepted by most virus workers. That it is untrue for the inclusion of trachoma is made probable by the work of Rice $^{18}$ showing that the matrix of the inclusion body is a carbohydrate which stains differently from the nucleus and cytoplasm of the cell and from phagocytosed bacteria and therefore cannot arise by phagocytosis of bacteria or cellular débris.

1 Summing up then we find thát the inclusion is a formation sui generis especially associated with the acute phase of infection, 
constantly present in trachoma, not found in other ocular conditions; closely related to infectivity; Almost certainly it contains the infective agent.

(2) Evidence from analogy.-Three other viruses are known which are closely related to trachoma morphologically, inclusion conjunctivitis, psittacosis and lymphogranuloma inguinale. In all these elementary and initial bodies occur and inclusions are found composed of elementary bodies, of initial bodies and of various mixtures of the two embedded in a more or less homogeneous ground substance or matrix. The inclusions of inclusion conjunctivitis cannot be distinguished from those of trachoma. Those of lymphogranuloma are similar but not identical. Many types of psittacosis inclusions are indistinguishable in ordinary specimens from those of trachoma though iodine staining by the method of Rice ${ }^{18}$ reveals a difference in the composition of the matrix. For psittacosis, the evidence is now complete that the elementary bodies are the infective agent since suspensions of them are specifically agglutinated by, and fix complement with, psittacosis anti-sera ${ }^{19}$. The work of Bedson and Bland 20 and Bland and Canti ${ }^{21}$ has shown that those inclusion bodies which are composed of masses of elementary bodies are derived from the other forms of inclusion by a process which they describe as a developmental cycle, the initial bodies forming the small, young, inclusions multiplying in number and reducing themselves in size until the large colonies of E.B.s are formed. That a similar cycle occurs in lymphogranuloma inguinale has been shown almost as conclusively as for psittacosis 22,23 , Less conclusive bút still very suggestive are Thygeson's ${ }^{24}$ observations on a similar cycle in inclusion conjunctivitis.

Where-such a close morphological similarity exists it seems reasonable to conclude that the inclusions of trachoma also represent colonies of the infective agent. The argument may be advanced that we must not trust too implicitly to morpholøgical similarities since things which look alike are not always the same. Fortunately, we now possess evidence from the work of Rake and his colleagues ${ }^{25}$ on complement fixation that these viruses are also related antigenically. This second coincidence so strongly supports the argument from morphological similarity that we can scarcely doubt its validity. The conclusion seems unavoidable that the inclusion bodies of trachoma are colonies of the infective agent.

Conclusive proof of this hypothesis could only be obtained :-

(1) $B y_{t}$ reproduction of the disease with purified suspensions of elementary bodies. It seemis unlikely that such suspensions will be made so long as we have to use material from the human conjunctiva. 
(2) By inoculation of isolated, washed inclusion bodies. This has been achieved in fowl-pox ${ }^{26}$ and might be achieved in trachoma though the technical difficulties would be much greater.

(3) By cultivation of inclusions through several passages in tissues-culture with proof of infectivity of the later subcultures. This has been attempted by many workers ${ }^{3,27,28,29}$. Of these, only Polef ${ }^{30}$ claims to have been successful in cultivating the inclusions but has not succeeded in proving their infectivity. Therefore, his experiments do not advance the matter.

\section{VI.-The Rickettsial theory of trachoma}

This hypothesis has been put forward in two forms : (1) That rickettsial bodies can be demonstrated in trachomatous tissues which are the cause of the disease and are distinct from the initial and elementary bodies; (2) That the initial and elementary bodies are the cause of trachoma and are themselves rickettsiae and not virus bodies. These two variants of the rickettsial theory are confused by some but it is essential we should examine them separately.

(1) A rickettsia; other than the initial and elementary bodies, is the cause of trachoma.-The proponent of this idea is Busacca $31,32,33,34$ who claims to have found in conjunctival epithelial cells and in cells from conjunctival follicles, minute bodies which, from their staining reactions and morphology he considers to be different from the elementary bodies and to be similar to rickettsiae. Similar bodies could be found'in the cells of the tunica vaginalis of guinea-pigs inoculated with trachomatous material. He himself ${ }^{34}$ considers that "the researches are too recent and too few as yet to permit the drawing of definite conclusions." Busacca's ideas at first received support from Cuénod and Nataf ${ }^{35,} 3637,38,39$ but later ${ }^{40}$ these authors appear tô think that the rickettsiae and the elementary bodies are one and the same. They have thus joined those who support the second variant of the rickettsial theory. Now ${ }^{41}$ they have departed still further from their original position and consider that, while trachoma ranks near the rickettsiae some characteristics of which it possesses, it nevertheless differs from them in other respects.

Busacca's findings have been criticised by Thygeson ${ }^{42}$ and by Braley ${ }^{43}$. The first was unable to find any rickettsial form except the elementary bodies in conjunctival cells and none at all in follicular material. In ślides sent him by Busacca and by Cuénod and Nataf he was unable to find any true rickettsiae but only grànules of a non-specific kind. Bengtson, to whom Thygeson submitted the slides, and who was at that time working with 
rickettsiae, confirmed Thygeson's findings. Braley ${ }^{43}$ demonstrated that the mitochondria and keratin granules of normal conjunctival cells can' be stained by Giemsa and' considers the bodies photographed by Busacca are undoubtedly these rather than rickettsiae.

There is general agreement as to the existence of the granules described by Busacca, Cuénod and Nataf but a divergence in the interpretation of their nature. While the evidence for the elementary and inclusion bodies as the infective agent is so strong we cannot accept Busacca's theory unless much more evidence can be found in its favour.

(2) The elementary and initial bodies are rickettsiae.-We -have seen that Cuénod and Nataf ${ }^{40}$ have come round to the idea that the rickettsiae described by Busacca and themselves are identical with the elementary bodies forming the inclusions. Polef ${ }^{44}$ has also given strong support to this idea on the grounds of certain observations of his own on tissue cultures. The chief advocates of this theory are, however, Foley and Parrot ${ }^{45,46}$. These authors do not advance any experimental evidence in support of their view but their work consists of a careful morphological comparison of the elementary, initial and inclusion bodies of trachoma with the rickettsiae of various diseases. They point out the close tinctorial similarities between the trachoma bodies and the rickettsiae and the tinctorial differences between trachoma and certain of the accepted visible viruses such as vaccinia and herpes. They further show that in certain rickettsial diseases intracellular formations very similar to trachoma inclusions occur. These similarities extend also to the viruses of inclusion conjunctivitis, lymphogranuloma inguinale and psittacosis and therefore these viruses are also classed as rickettsiae by Foley and Parrot. The question thus becomes one of the taxonomic position of this whole group and as such will be considered in the final section of this review. As against the conclusions of Foley and Parrot stands an equally careful morphological comparison of trachoma with the typical rickettsiae of typhus, Rocky Mountain spotted fever, $Q$ fever and nine mile fever made by Bengtson ${ }^{47}$. She concludes that "morphologically the inclusion is rather distinct from the rickettsiae."

There remain to be discussed two further pieces of evidence which favour the rickettsial theory. The alleged occurrence of a positive-Weil-Felix reaction in trachoma and the evidence for transmission of trachoma by lice.

(3) The occurrence of a positive Weil-Felix reaction in Trachoma.-The first suggestion that the Weil-Felix reaction might be positive in trachoma came from Derkac ${ }^{48}$. Since then many authors have reported on this subject, some claiming that 
the test is significant and of diagnostic value, others denying that it is more often positive in trachoma than in a representative sample of the normal population. Even those who claim positive results do not claim that the titre rises above $1 / 100$ in the majority of cases. Surely such evidence does not warrant the conclusion that trachoma is a rickettsial disease. The subject has been well reviewed by Bengtson ${ }^{47}$ and by Polef ${ }^{49}$.

(4) The transmission of trachoma by lice.-Cuénod and

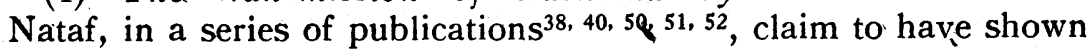
that the granules found by them in trachomatous tissue can multiply in the body-louse when the material is inoculated per anum. Rickettsiae are found in the intestines of the inoculated lice and their ground-up bodies cause experimental trachoma even after six successive passages in lice. In the majority of these experiments the test object was M. inuus which has not yet been shown to pass the necessary. tests demanded by this review. Strictly, therefore, these results must be rejected. On one occasion, however ${ }^{40}$, ground lice containing rickettsiae infected a human being and this must be accepted as proving that the lice were infective. Trapezontzewa ${ }^{53}$, in a scholarly critique of these experiments, supported by an experimental study of her own; shows that Cuénod and Nataf have not excluded the possibility that the cultivated lice used by them were infected with naturally occurring rickettsiae, for if batches of apparently healthy lice, in which rickettsiae cannot be found, are ground up and used as inoculum for further lice, spontaneous rickettsiae appear in the second or third passage. She could not confirm the infectivity of lice infected with trachoma material. Weigl ${ }^{54}$ also has been unable to confirm Cuénod and Nataf's experiments and denies their statement that $R$. rocha-lima is the causative agent of trachoma since he could detect no agglutinins against this rickettsia in the sera of trachomatous patients even when thęse had a relatively high titre for proteus OX19, OXK and R. prowazeki.

In view of these criticisms we cannot accept.Cuénod and Nataf's claim that rickettsiae from trachoma multiply in the louse and are the cause of the disease. The most that they can legitimately claim,-on the basis of their experiment in man, is that the agent of trachoma may survive in the louse and retain its infectivity. No evidence has yet been produced that in nature lice are vectors of the agent of trachoma. Stewart ${ }^{11}$ has indeed produced evidence which bears against it. 173 Pediculus capitis from 15 children with early trachoma and 379 - corporis from similar cases were used to infect three baboons.- No trachoma resulted but the number of animals used is too small for the result to be significant. . 


\section{VI.-Discussion}

In the course of this review we have seen that the available evidence shows that trachoma is an infectious disease caused by a non-cultivable, filterable agent, identical with the elementary and initial bodies found in the Prowazek-Halberstaedter inclusions, and bearing a close natural relationship to the viruses of inclusion conjunctivitis, lymphogranuloma inguinale and psittacosis. There is no evidence that this agent possesses an arthropod host, nor that the louse is a vector of the disease though the agent may survive for some days in the body of theilouse. In what group of organisms are we to place this agent along with the three other agents to which it is related? Are we to consider them rickettsiae or viruses? Since at present there is not complete agreement among bacteriologists as to the precise definition of the genus rickettsiae and since the virus group is largely defined by negative characteristics and pośsibly contains agents of very different intrinsic nature which a natural biological classification would not place together, the matter becomes largely one of personal choice. Undoubtedly, those four agents resemble the rickettsiae in a number of points; they are minute in size and show pleomorphism, though not the bacillary and thread forms of typical rickettsiae; they do not stain easily with aniline dyes; they are Gram-negative; they stain easily with Giemsa and in their various morphological forms take a variety of tints from red to dark blue with this stain; they stain easily and specifically with Castañeda's stain; they are only little, if any, more filterable than rickettsiae; they are noncultivable apart from living cells; they adopt an intracellular habitat. They differ from the majority of the rickettsiae in not possessing an arthropod host. In what respects do they differ from or resemble a typical large virus such as vaccinia? Up to the present, true initial bodies with basophil staining properties have not been described in a typical virus. Bland and Robinow ${ }^{55}$ suggest that in vaccinia the smallest type of inclusion body is an analogue' of the initial body, but its tinctorial quality is different. Lack of staining with aniline dyes and Gram-negativity are points in common with viruses as well as rickettsiae. The ease of staining of the four agents with Giemsa is not so much greater than that of vaccinia as to be relied on as a.distinguishing character and the free elementary bodies of these agents take the same colour as vaccinia with this stain. Vaccinia does not stain with Castañeda's stain. Trachoma appears to be certainly less filterable than vaccinia but psittacosis is not greatly so. Noncultivability and intracellular habitat are points which are shared both by viruses and rickettsiae. We may say then that these 
four agents differ from the typical large virus : (1) In possessing initial bodies which stain blue with Giemsa and in showing greater pleomorphism; (2) In forming inclusions with a basophilic matrix; (3) In staining with Castañeda's stain. They differ from typical rickettsiae : (1) In lack of an arthropod host; (2) In not showing bacillary and thread forms; (3) In forming inclusions with a matrix. The four agents thus possess points of resemblance to both rickettsiae and viruses and some points in which they differ from both.

I myself consider that they stand in an intermediate position between the rickettsiae and the large viruses and may possibly form a biological link between them. For the present, I would prefer to group them with the viruses but to give them a distinctive position as the " basophilic viruses". on account of the blue staining of their initial bodies and of the matrix of their inclusions which distinguishes them from the larger typical viruses which do not possess blue initial bodies and whose inclusions are acidophilic.

\section{REFERENCES}

1. Wilson, R. P.-Congrès. Internat. Med. Trop. and Hyg., Cairo, Vol. III, p. $651,1938$.

2. Bertarell1, E. and Cechetto, E.-Zentralbl. Bakt., Vol. XLVII, 1 Abt. orig., p. 432, 1908.

3. Julianflie, L. - The Etiology of Trachoma. New York, The Commonwealth Fund, 1938.

4. Nicolle, C. and Lombroso, U.-Rev. du Trach., Vol. III, p. 71, 1936.

5. Noguchi, M.-Jl. Exp. Med., Vol. XLVIII, Supplement No. 2, 1938.

6. Bertarelli, E. and Cechetto, E.-Zentralbl. Bakt., Vol. L, p. 241, 1 Abt. orig., 1909.

7. Nicolle, C., Cuénod, A. and Blaizot, L.-C. R. Acad., Vols. III and IV, p. 241, 1912.

8. Nicolle, C:-Bull. Inst. Past., Vol. XIX, p.,881, 1921

9. Julianelite, L. and Harrison, R. W.-Amer. Jl. Ophthal., Vol. XVI, p. $857,1933$.

10. Olitsky, P. K., KNutti, R. E. and Tyler, J. R.-Jl. Exp. Med., Vol. LIV, p. 557,1931 ,

11. Stewart, F. H. -12th Ann. Rep. Mem. Ophthal. Lab., Giza, Appendix 1, Cairo, 1937.

12. Rev. Internat. du Trach., Vol. XV, p. 33, 1938.

13. Thygeson, P. and Proctor, F. I,-Arch. Ophthal., Vol. XIII, p. 1018, 1935.

14. ThYgeson, P., Proctor, F. I. and Riçhards, P.-Amer.Jl. Ophthal., Vol. XVIII, p. 811, 1938.

15. Julianelie, L.-Amer. Jl. Ophthal., Vol. XXIII, p. 633, 1940.

16. TABORISKY, J.-Arch. Ophthal., Leipzig Vol. CXXIV, p. .455, 1930.

17. Wilson, R. P.-Ann. Rep. Mem. Ophthal. Lab. Giza, Cairo, Vol. XI, p. 13, 1936.

18. RICE, C. E.Amer. Jl. Ophthal., Vol. XIX, p. 1, 1935.

19, BEDSon, S.P.-Brit. Jl. Exp. Path. Vol. XIII, p. 65, 1932.

20. Bedson, S. P! and Bland, J. O. W.-Brit. Jl. Exp. Path., Vol. XIII, p. 461, 1932.

21. Bland, J. O. W. and CANti, R. G.-Jl. Path. and Baçt, Vol, XI, p. 231, 1935.

22. Findiay, G. M., Mackenzie, R: P. and MacCallum, F. C.-Trans. Roy. Soc. Med. Hyg., Vol. XXXII, p. 183, 1938.

23. RAKE, G. and JoNes, H. P.-Jl. Exp. Med., Vol. LXXV, p. 323, 1942. 
24: Thygeson, P.-Amer. Jl. Ophthal., Vol. XVII, p. 1019, 1934.

25. RAKe, G.. Shaffer, M.F. and Thygesón, P.-Proc. Soc. Exp. Biol. Med., Vol. XLIX, p. 545, 1942.

26. WoodrufF, C. E. and Goodpasture, E. W.-Amer. Jl. Path., Vol. V.p. I, 1929.

27. Julianelle, L.-Amer. Jl. Ophthal., Vol. XXVI, p. 280, 1943.

28. Thygeson, P.-Arch. Ophthal., Vol. XXI. p. 229, 1939.

29. SANton, A.-Ann. d'Ottal. e Clin. Ocul., Vol. LXVIII, p. 32, 1940.

30. Pole F, F.-Rev. Internat. du Trach., Vol. XVI, p. 79, 1939.

31. Busacca, A. - Folia Clin. Biol., Sao Paulo, Vol. V, p. 96, 1933.

32. Rev. Biol. Hyg., Vol. V. p. 86, 1934.

33. - Arch. d'Ophtal., Vol. LiI, p. 557, 1935.

34. Arch. Ophthal., Vol. XVII, p. 117, 1937.

35. Cuénod, A.-Arčh. Lnst. Past.. Tunis, Vol. XXIV, p. 86, 1935.

36. Arch. d'Opthal., Vol. LII, p. 145, 1935.

37. CUÉNOD, A. and NATAF, R-Rev. Internat. du Trach., Vol. XII, p. 110, 1935.

38. Arch. d'Ophtal., Vol. LII, p. 573, 1935.

39. - Arch. d'Ophtal., Vol. LVI, p. 218, 1936

40. Brit. Jl. Ophthal., Vol. XXI, p. 309, 1937.

41. Ophthalmologica, Vol. XCVII, p. 277, 1939.

42. THY.geson, P.-Arch. Ophthal., Vol. XX, p. 16, 1938.

43. BRALEY.-Arch. Ophthal., Vol. XXI, p. 735, 1939.

44. Polef, L.-Arch: d'Ophtal., Vol? LIII, p. 882, 1936.

45. Foley, M. and PARROT, L.-C. R. Soc. Biol., Vol: CXXIV, p. 230, 1937.

46. Arch. Inst. Past. Algérie, Vol. XV, p. 339, 1937.

47. Bengtson, I. A.-Amer. Jl. Ophthal, Vol. XXIII, p. 770, 1940.

48. DERKAC, V.-Klin. Monatsbl. f Augenheilk., Vol. XCIX, p. 596, 1937.'

49. POLEF, L.-Ophthalmologica, Vol. CIV, p. 121, 1942.

50. Cú́NOD, A. and NATAF, R.-Arch. Inst. Past., Tunis, Vol. XXV, p. 595, 1936.

51. - Rev. Internat. du Trach., Vol. XIV. p. 104, 1937.

52. - Rev. Internat. du Trach., Vol. XIV, p. 117, 1937.

53. TRAPEZONTZEWA, C.-Rev. Internat. du Trach., Vol. XVI, p. 40, 1939.

54. WeIGL, C.-Zentralbl. Bakt, Vol. XCIV, March, 1939.

55. Bland, J. O. W. and Robinow, C. -Jl. Path. Bact., Vol. XLIX, p. 381, 1939.

56. Blan D, J. O. W.-Jl. Path. Bact., Vol. LVI, p: 161, 1944.

57. - Ji. Path. Bact., in press, 1944.

58. Stewakt, F. H.-9th. Any. Rep. Mem. Ophthal. Lab., Giza, p. 95, 1934.

\title{
AN ANALYSIS OF ONE HUNDRED CASES OF STRABISMUS TREATED ORTHOPTICALLY*
}

\author{
BY \\ R. U. GILLAN \\ WALSALL AND WEST BROMWICH
}

AN orthoptic department was started at the West Bromwich and District Hospital in March, 1941, not without some trepidation, as to whether the amount of work would justify the inception of such a department, and as to whether the work itself was really worth while. Fears regarding the amount of work were quickly dispelled by the rapid accumulation of a large waiting-list which

- Received for publication, November 25, 1944. 